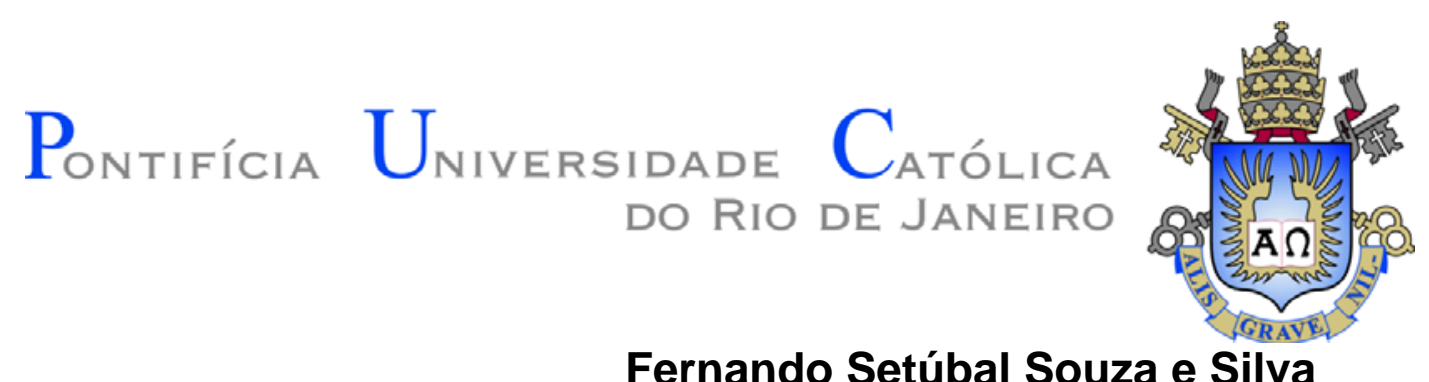

Inflação Como Determinante da Expansão
do Sistema Bancário Brasileiro

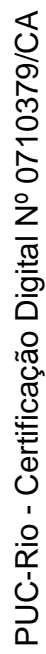

Dissertação de mestrado

Dissertação apresentada como requisito parcial para obtenção do título de Mestre pelo Programa de PósGraduação em Economia da PUC-Rio.

Orientador: Prof. Juliano Assunção

Rio de Janeiro

março de 2009 


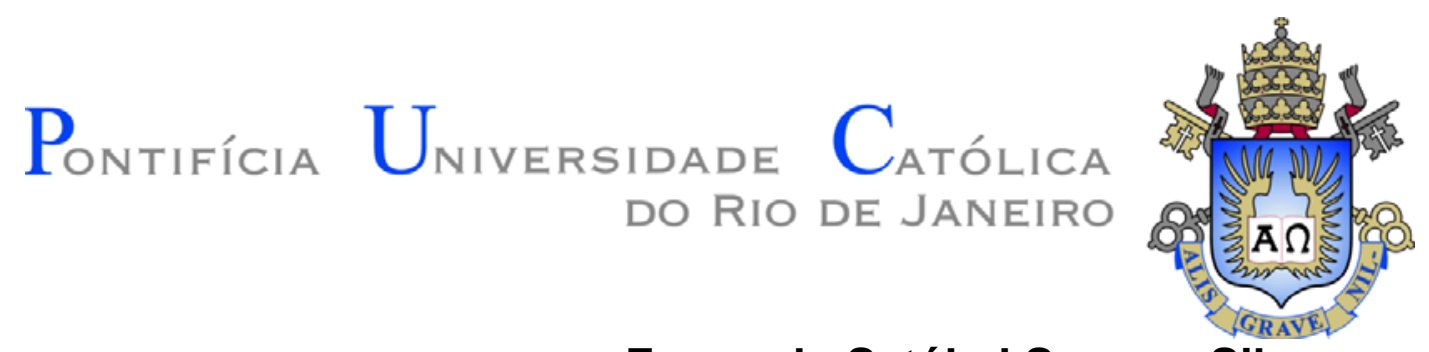

Fernando Setúbal Souza e Silva

\section{Inflação Como Determinante da Expansão do Sistema Bancário Brasileiro}

Dissertação apresentada como requisito parcial para obtenção do título de Mestre pelo Programa de PósGraduação em Economia da PUC-Rio. Aprovada pela Comissão Examinadora abaixo-assinada.

Prof. Juliano Assunção Orientador PUC-Rio

Prof. João Manoel Pinho de Mello PUC-Rio

\section{Prof. Christiano Arrigoni Coelho} Banco Central do Brasil

Prof. Nizar Messari Coordenador(a) Setorial do Centro de Ciências Sociais - PUC-Rio 
Todos os direitos reservados. É proibida a reprodução total ou parcial do trabalho sem autorização da universidade, do autor e do orientador

Fernando Setúbal Souza e Silva

Graduou-se na USP em ciências econômicas

Ficha Catalográfica

Silva, Fernando Setúbal Souza e Silva

Inflação Como Determinante da Expansão do Sistema Bancário Brasileiro/Fernando Setúbal Souza e Silva; orientador: Juliano Assunção - Rio de Janeiro: PUC-Rio. Departamento de Economia. 2009.

49f; $30 \mathrm{~cm}$

Dissertação (Mestrado em Economia) - Pontifícia Universidade Católica do Rio de Janeiro, Rio de Janeiro, 2009

Inclui bibliografia

1. Economia - Teses. 2. Desenvolvimento financeiro, 3. Setor bancário, 4. Inflação I. Juliano Assunção. II. Pontifícia Universidade Católica do Rio de Janeiro. Departamento de Economia. III Título

CDD: 330 


\section{Agradecimentos}

Agradeço ao meu orientador (e amigo) Juliano por ter tido sempre disposição e paciência para me ajudar quando foi solicitado. Aos professores Léo e Gustavo por terem me recebido de braços abertos no meu curso de pósgraduação. Ao Christiano e ao João Manoel por terem contribuído decisivamente para a evolução do trabalho com sugestões. A Graça e a Bianca por terem me aguentado. A CAPES pelo apoio financeiro.

Agradeço também ao meu avô pelo incentivo para que eu cursasse o mestrado em economia; se estivesse entre nós, ele certamente teria interesse pelo tema. A minha noiva Paulinha por ter apoiado de maneira incondicional a minha vinda ao Rio e estar sempre ao meu lado. Aos meus pais que sempre me ajudaram nos momentos mais difíceis e se dispuseram a me visitar periodicamente. Aos meus queridos irmãos, cada um ao seu jeito, que participaram, vivenciaram e se preocuparam comigo. Aos meus tios Fredo e Beto pelas conversas, ajudas e conselhos. Sem esse apoio, a qualidade do trabalho certamente seria menor. Ao amigo Sérgio Werlang, que sempre me aconselhou e me ajudou nas mais diversas e difíceis situações. A Ana Carla Costa pela ajuda para conseguir os dados. Aos meus amigos (até os 80?) do Time do Zé, sempre companheiros e que tantas vezes vieram me visitar. Aos frequentadores dos “esquentas" no apartamento do tio Ruy. A todos que vieram me visitar, em especial, ao Du, Mariano, Digão, Bolacha, Penin e Alex que ficaram em casa por alguns dias durante as férias ou a trabalho. A todos os amigos, ortodoxos e heterodoxos, com quem eu tive o prazer de discutir economia. Ao Rudi, Joana, Ique, Bel Murat, Rosalina e Lichand, que leram e deram sugestões valiosas para a melhoria do trabalho. Aos meus colegas de PUC, pela convivência. 


\section{Resumo}

Silva, Fernando Setúbal Souza; Juliano Assunção (orientador). Inflação como determinante na expansão do sistema bancário brasileiro. Rio de Janeiro, 2009. 49p. Dissertação de mestrado - Departamento de Economia, Pontifícia Universidade Católica do Rio de Janeiro.

A dissertação analisa como a inflação afeta a expansão do sistema financeiro. O Brasil oferece uma oportunidade de pesquisa peculiar, pois conviveu por muitos anos com inflação superior a $1.000 \%$ a.a. e que caiu abruptamente a ponto de, pouco mais de um ano depois do bem-sucedido plano de estabilização, estar próxima a 10\%. O resultado principal é que com inflação elevada, os bancos expandem agências mais interessados em captação vis-à-vis crédito. Por outro lado, com a inflação controlada os bancos passam a ter mais interesse no crédito. Os dados sugerem ainda que houve uma mudança no padrão de expansão das variáveis financeiras (agência, crédito e captação) com relação às características dos municípios como tamanho de mercado, posição geográfica, nível de desenvolvimento e infraestrutura. Esta evidência reforça a tese de que o sistema financeiro brasileiro passou por uma mudança estrutural com o fim da inflação. A dissertação enfatiza a importância do ambiente institucional para o desenvolvimento do mercado de crédito.

\section{Palavras-chaves}

Desenvolvimento financeiro, sistema bancário e inflação 


\section{Abstract}

Silva, Fernando Setúbal Souza; Juliano Assunção (advisor). Inflation as a determinant in the expansion of the Brazilian banking system. Rio de Janeiro, 2009. 49p. M.A. Dissertation - Departamento de Economia, Pontifícia Universidade Católica do Rio de Janeiro.

This dissertation analyzes the effects of inflation on the expansion of the financial system. To this end, Brazil provides a singular opportunity for research as the country experienced inflation of more than $1,000 \%$ per year for many years followed by an abrupt drop. Slightly more than a year after implementation of a successful stabilization plan it was close to $10 \%$. The main result is when inflation is high, banks expand their branch network, more interested as they are in capturing funds as opposed to granting credit. On the other hand, when inflation is under control, banks begin to focus more on credit. The data also suggest that there was a change in the growth pattern of financial variables (branch, credit, and CD issuing) as related to characteristics of the municipalities such as market size, geographical location, level of development, and infrastructure. This evidence reinforces the premise that the end of inflation prompted structural change in the Brazilian financial system. The dissertation emphasizes the importance of the institutional environment for the development of the credit market.

\section{Keywords}

Financial development, banking system, and inflation 


\section{Sumário}

1. Introdução

2. Conjuntura econômica 11

2.1. O inflacionismo no Brasil 11

2.2. O fim da inflação e o sistema financeiro 12

$\begin{array}{ll}\text { 2.3. A escolha dos períodos } & 13\end{array}$

3. Estatísticas descritivas 15

4. Resultados 18

4.1. Crescimento das agências. Qual o principal determinante: Ativo ou Passivo?

4.2. Os determinantes do crescimento da agência, do crédito e da captação

5. Robustez

6. Conclusão 